\title{
Women's Socio-Economic Status as a Determinant of Utilization of Antenatal Care in Primary Health Centres: A Case Study of Nando Community, Anambra East Local Government Area, Nigeria
}

\author{
Okoronkwo Ijeoma $^{1^{*}}$, Adeyemo Florence ${ }^{2}$, Nnamdi Nneka ${ }^{1,3}$, Ada Nwaneri ${ }^{1}$ and Chjkaoodili Ihudiebube ${ }^{1}$ \\ ${ }^{1}$ Department of Nursing Sciences, University of Nigeria, Enugu \\ Campus, Enugu Nigeria. \\ ${ }^{*}$ Corresponding author \\ Okoronkwo Ijeoma, Department of Nursing Sciences, University \\ ${ }^{2}$ Department of Nursing, Ladoke Akintola University of Technology, \\ College of Health Sciences, Osogbo, Nigeria. \\ of Nigeria, Enugu Campus, Enugu Nigeria, E-mail: ijeoma. \\ okoronkwo@unn.edu.ng. \\ Submitted: 30 Dec 2016; Accepted: 20 Jan 2017; Published: 26 Jan 2017
}

${ }^{3}$ School of Nursing, Amachara, Abia State.

\begin{abstract}
The study examined the association between women's status and utilisation of maternal health care services of primary health care centres in Anambra east L.G.A of Anambra state. Five objectives were developed. A cross sectional descriptive research design was used. The study population consisted of women of child bearing age (15-49 years) who had given birth in the last five years. A sample size of 500 participants was used after using the formula for estimating sample size from a finite population. However, only 482 copies of the questionnaire were returned, giving a response rate of $96.4 \%$. The instrument for data collection was a questionnaire developed by the researchers based on literature review. Data were analysed using the statistical package for the social sciences (SPSS version 18). The major findings showed that $71.5 \%$ utilised ANC while $44.4 \%$ utilised delivery healthcare services; $40.2 \%$ of the women took decisions jointly with their husbands while $32.4 \%$ took decisions alone on utilisation of ANC. As regards utilisation of delivery care services, $39 \%$ took decisions alone while $36.5 \%$ took decisions jointly with their husbands on where to have their baby. There were statistical significant associations between women decision making autonomy women education, women economic status and utilization of maternal health services. However, the study showed no statistical significant association between occupational status and utilisation of maternal health care services. The study concluded that the factors that influence the utilisation of maternal health care services are women decision making autonomy, educational status and their economic status.
\end{abstract}

Keywords: Socio-economic status, Primary Health Centres (PHC), Antenatal Care.

\section{Introduction}

Antenatal care is the care received from healthcare professionals during pregnancy, where series of appointments are offered by midwives, or sometimes with an obstetrician [1]. the well being of pregnant mothers are checked and useful information (including healthy feeding, exercise and advice on personal hygiene) given to ensure that the pregnancy progresses well. Health education including breastfeeding is also offered. Fawole and Adeoye stated that proper care during pregnancy and delivery is important for the health of both the mother and the baby because it is an indicator of the status of maternal and child health in the society [2].

The health risk associated with reproduction affect virtually all women of reproductive age at some point in their lives [3]. These risks are more marked in developing countries where majority of the women are poor and have low economic status [3]. This low status deprives them of the decision-making power necessary to take prompt decisions on health care. In developed countries where women are educated and earn a reasonable income, they have the power to make decisions concerning their health and have access to basic maternal health care services [3]. The utilization of maternal health care services, especially at the primary level, is one of the important factors that will help reduce the incidence of maternal mortality [4].

The use of health services is a complex behavioural phenomenon. It is related to the organization of the health-delivery system and is affected by the availability, quality, costs, continuity and comprehensiveness of services. Social structure and health beliefs also affect use [5,6]. For preventive services like prenatal care, family planning or immunizations, people do not perceive the need to visit health care facilities in absence of disease $[5,6]$. Beliefs about susceptibility, consequences and effectiveness of intervention also affect the utilization of health care services [7]. However, some studies in preventive services have often 
found that the use of services is more strongly correlated with demographic and socioeconomic characteristics than with health beliefs [8]. Many studies in developing nations have found a strong relationship between maternal education and the use of maternal and child health services $[9,10]$. In some of these studies, the effect of education persisted even after the control of other variables $[10,11]$.

A woman's status which is often described in terms of her income, employment, education, health and fertility as well as the role she plays within the family, community and the society has been closely linked to use of antenatal care [3,12]. Women autonomy and utilisation of maternal care services are positively related [13]. According to authors, women's autonomy is dependent on many factors, the most important being education, place of residence (rural or urban), occupation and income. Women, who live in the urban areas, are generally educated and employed. They have a higher status and more decision making autonomy than those who live in the rural areas $[9,14]$. Poor mothers are at high risk of developing pregnancy related complications, because they are not financially able to pay for the required services [15].

In developing countries particularly in Nigeria, availability and utilization of maternal healthcare services are low [16]. It was estimated that only $13.9 \%$ of annual birth in 12 states in Nigeria took place in the health facilities [16]. Ajaegbu noted that culture and educational status of mothers influence their utilisation of maternal health services [17]. In Nigeria, especially in the rural areas, many factors affect utilization of maternal health services. They include health and religious beliefs about complications of pregnancy, financial factors and accessibility of health facilities. Other factors include the fact that permission has to sought from the husband before seeking healthcare services $[9,16,18]$. According to the WHO, there are three crucial factors underlying maternal deaths: Firstly, lack of access and utilization of essential obstetric services. Secondly is too much physical work together with poor diet which also contributes to poor maternal health outcomes [19]. The third is the low social status of women in developing countries. The low status of women can limit their access to economic resources and basic education, and can also affect their ability to make decisions, including decisions related to their health and nutrition. Not much study has been done on the association between women's status and maternal health care service utilisation in the south east of Nigeria. This study therefore investigated the association between women's status and maternal use of primary health care facilities in Nando, Anambra East Local Government Area of Anambra State.

\section{Statement of Problem}

Nigeria's maternal mortality rate is considered to be one of the highest in the world $[18,20]$. Although Nigeria accounts for only $2 \%$ of the world's population, it accounts for $10 \%$ of the global estimates for maternal deaths. This is as a result of widespread ignorance, harmful cultural practices and limited access to health service $[16,18]$. There is also documented evidence of underutilization of available health services; this has greatly contributed to the high maternal mortality ratio in the country. In many developing countries such as Nigeria, Ethiopia and others, women are at a disadvantage, compared to men in terms of their access to assets, employment, healthcare and education. Women's perceived inferior social status and status within the family have adversely affected their health by limiting their autonomy to take decisions on their health and ability to access health care where and when necessary $[21,22]$. Hence this study sought to determine if there is a relationship between women's socio-economic status and utilization of health centres in Nando community.

\section{Objectives of the Study}

The objectives were to:

- Determine the proportion of women that utilized antenatal care services in primary health centres in Nando.

- Determine the association between women's decision making autonomy and use of antenatal care service in primary health care centres.

- Determine the association between educational status of women and use of antenatal care service in primary health care centres in Nando.

- Determine the association between occupational status and use of antenatal care service of primary health care centres in Nando.

- Determine the association between women economic status and use of antenatal care service of primary health care centres in Nando.

\section{Research Method}

Research Design

Descriptive design was employed to assess the association between women status and use of antenatal care service of primary healthcare centres in the Nando community.

\section{Population of Study}

The population of study were women of child bearing age. The population of women of child bearing age in Nando is estimated to be 7920 . This number therefore represents the target population.

Sample

The final sample size used for this study was 500 women of child bearing age. A prevalence rate of $0.12 \%$ found in a survey of determinants of maternal health care utilisation in Nigeria was used [23]. The minimum sample size of 450 was calculated using the formula for estimating a single finite population [8].

The sample size was then adjusted to accommodate the attrition rate. The researcher estimated a $10 \%$ attrition rate. This attrition rate is to accommodate those questionnaires that will be disqualified for any number of reasons such as questionnaires not properly filled or those who were simply not returned. The final sample size of 500 was used after adding the $10 \%$ attrition rate.

\section{Inclusion Criteria}

- All women who had been pregnant in the last 5 years irrespective of the outcome of pregnancy, whether the 
pregnancy was terminated half way or carried to term.

- Women, who are alert and physically capable of being interviewed

- Women who are residing in the community at the time of the study.

- Women who are willing to participate in the study.

\section{Sampling Procedure}

The sampling technique used was the multistage sampling technique. The women were stratified into eight communities. Hence, each community was regarded as stratum. The population of women from each community was obtained from the women's meeting register. Proportionate sampling method was used to select a representative sample size of childbearing women from each community using the following formula $[24,25]$.

Where $\mathrm{ns}=$ sample size of the village; $\mathrm{Ns}=$ population size of

$$
\begin{aligned}
& \qquad n_{S}=\frac{N_{S} *}{N} \\
& \text { the village; } \mathrm{N}=\text { total sample size. }
\end{aligned}
$$

To get the number of women in each community, a systematic sampling technique was used. At this stage the women's register was used as the sampling frame to reach the respondents who met the inclusion criteria. Every second woman on the register was selected if she met the inclusion criteria. This was done until the required number for the community was obtained. The women were interviewed during their meeting hours using the questionnaire as a guide.

\section{Instrument for Data Collection}

The instrument for data collection was the questionnaire. The questionnaire was divided into three parts. Part A had 8 questions and dealt with demographic data of the individuals. Part B had 9 questions that sought to determine if and where the women had their ANC services. This section also sought to determine how decisions were taken concerning use of ANC services. Part C had 9 questions on the economic status of the respondents. Questions on household assets were elicited which included having facilities in the home such as electricity, pipe borne water, toilet and type of floor in the house. Other questions included items owned in the homes; example radio, television and bicycle were elicited. This enabled classification of respondents into socio-economic status groups. The questionnaire was used as an interview guide.

\section{Validity of the Instrument}

Face and content validity were carried out by giving the questionnaire to experts in Maternal and Child Health Nursing for criticism and suggestions and corrections were made to construct the final draft of the questionnaire.

\section{Reliability of the Instrument}

pilot testing was done using fifty women from the neighbouring Achalla community that met the inclusion criteria and were not instead of are not part of the study population. Ideally, in order to obtain a good estimate of the reliability of the instrument, tthe split half method was applied by dividing the test items into two parts with the exception of the demographic characteristics and also the subjects into two groups before administering the questionnaire. This is called split-half test. The responses were subjected to internal consistency test using the Cronbach's alpha coefficient for each of the split halves $1 \& 2$. The results obtained were 0.802 and 0.835 respectively, and the correlation between forms is 0.854 , indicating a very strong reliability.

\section{Ethical Consideration}

Ethical approval to conduct the study was obtained from the health research ethical committee of Anambra State teaching hospital, Awka after submitting a copy of the proposal of the study to the committee. Informed consent was gained from the respondents before giving them the questionnaire. The purpose of the study was explained to them. They were also assured of confidentiality of whatever information that they will give. The respondents were also given the option to withdraw anytime they felt uncomfortable.

\section{Procedure for Data Collection}

Data were collected from participants who were willing to participate and those who met the study inclusion criteria. Four research assistants were trained on the purpose of the study, how to collect data and interpret the questionnaire to the respondents. The researchers and her assistants visited the women's meeting places in their various communities and the women's register was used as the sampling frame to systematically select the number of women required. Every 2nd name on the register was selected if she met the inclusion criteria and was willing to participate. Informed consent was then obtained before interviewing her using the questionnaire as a guide. This procedure was carried out until the required number was reached in all communities. For respondents that could not read or write in English language, local interpreters (the research assistants) were used to translate the questionnaire into the local language ensuring that the same meaning was maintained to ensure consistency and reliability of the instrument. Data collection in each community lasted for 8 days. Data collection was done during the women's meeting day which is every 4 days (market days) data collection lasted for six weeks.

\section{Method of Data Analysis}

Data collected were coded and analysed using descriptive and inferential statistics. This was done using the computer software programme, Statistical Package for the Social Sciences (SPSS version 18). The principal component analysis was used to generate Socio economic status (SES) index based on the household assets ownership. The SES index was divided into quartiles: Q1 = Poorest, Q2= Very poor, 3= poor, Q4= Least poor. The one-way analysis of variance statistics was used and alpha was set at $95 \%$ confidence interval.

\section{Results}

Research question one

What is the proportion of women that utilise ANC services in primary health care centres in Nando? One sample t-test was used 
to answer this research question at 0.05 level of significance and presented in Table 1.

\begin{tabular}{|c|c|c|c|c|c|c|}
\hline Variable & N & Df & Mean & SD & t-value & Sig. \\
\hline Utilization of ANC & 482 & 481 & 27.22 & 2.96 & 7.91 & .000 \\
\hline Population mean & & & 25.0 & & & \\
\hline
\end{tabular}

Table 1: one sample t-test of proportion of women utilization of ANC services.

Reference mean or population mean is calculated thus $(4+3+2+1) \times 10 / 4=25.00$

The result presented in Table 1 assessed utilization of ANC services in primary health care centres in Nando. The sample mean of 27.22 is greater than the reference/population mean of 25.00 at 0.05 level of significance at 481 degree of freedom. It can be inferred that the proportion of women that utilise ANC services in primary health care centres in Nando is significantly high.

\section{Research question two}

What is the association between women decision making autonomy and the use of ANC services in primary health care centres in Nando? Independent sample t-test was used to answer this research question and presented in table 2 .

\begin{tabular}{|c|c|c|c|c|c|}
\hline Grouping variable & $\mathbf{N}$ & Mean & SD & t-value & Sig. \\
\hline Have autonomy & 362 & 13.3 & 3.14 & 4.51 & $.001^{*}$ \\
\hline Do not have autonomy & 120 & 7.11 & 4.52 & & \\
\hline
\end{tabular}

Table 2: independent t-test of women decision making autonomy and utilization of ANC services. ${ }^{*}$ Significant at 0.05 level of significance; $\mathrm{df}=$ 480 ; critical t-value $=1.96$.

The result as presented in Table 2 shows that, the calculated t-value of 4.51 is greater than the critical t-value of 1.96 at 480 degree of freedom. This result implies that, the association between women decision making autonomy and the use of ANC services in primary health care centres in Nando is statistical significant. Judging with the mean score, it can be said that, women who claimed to have decision making autonomy have a higher mean value $(M=13.3$; $\mathrm{SD}=3.14)$ than women who claimed not to have decision making autonomy $(\mathrm{M}=7.11$; $\mathrm{SD}=4.52)$. The result means that women who possess more decision making autonomy are more likely to utilise ANC services than those who do not posses decision making autonomy.

\section{Research question three}

What is the association between educational status of women and the use of ANC services in primary health care centres in Nando? To answer this research question, One-way analysis of variance (ANOVA) was used at 0.05 level of significance. The results obtained from the analysis are as presented in table 3 .

One-way analysis of variance (ANOVA) was used to analyze the data. The result is presented in Table 3. As shown in Table 3, the calculated F-value of 8.90 is greater than the critical F-value of 7.00 at 2 and 480 degrees of freedom, at 0.05 levels of significance by this results, the association between educational status of women and the use of ANC services in primary health care centres in Nando is statistically significant. Judging with the mean scores, it can be said that, women without formal education have the least mean score value of $(\mathrm{M}=15.40 ; \mathrm{SD}=2.33)$; next in the list are women with just primary education $(\mathrm{M}=15.58$; $\mathrm{SD}=2.31)$; followed by women with secondary school education $(\mathrm{M}=16.0$; $\mathrm{SD}=2.53$ ) while the group with the highest mean are women with tertiary education $(\mathrm{M}=17.48 ; \mathrm{SD}=2.14)$. The result implies that, women who possess more education are more likely to utilise ANC services than those who possess little or no education.

\begin{tabular}{|c|c|c|c|c|c|c|}
\hline Variable & Category & $\mathbf{N}$ & Mean & SD & & \\
\hline \multirow{5}{*}{$\begin{array}{c}\text { No formal } \\
\text { education }\end{array}$} & 48 & 15.40 & 2.33 & & \\
\cline { 2 - 7 } $\begin{array}{c}\text { Educational } \\
\text { status }\end{array}$ & Secondary & 202 & 16.00 & 2.53 & & \\
\cline { 2 - 8 } & $\begin{array}{c}\text { Sertiary } \\
\text { Source of } \\
\text { variance }\end{array}$ & $\begin{array}{c}\text { Sum of } \\
\text { Squares }\end{array}$ & df & $\begin{array}{c}\text { Mean } \\
\text { Square }\end{array}$ & F & Sig. \\
\cline { 2 - 8 } & $\begin{array}{c}\text { Between } \\
\text { Groups }\end{array}$ & 7.130 & 2 & 3.565 & 8.900 & $.000^{*}$ \\
\cline { 2 - 8 } & $\begin{array}{c}\text { Within } \\
\text { Groups }\end{array}$ & 375.744 & 480 & .401 & & \\
\cline { 2 - 8 } & Total & 382.874 & 482 & & & \\
\hline
\end{tabular}

Table 3: One-way analysis of variance of educational status of women and the use of ANC services. *Significant at 0.05 level of significance, $\mathrm{df}$ $=2,480$; critical F-value $=3.00$.

\section{Research question four}

What is the association between occupational status and use of ANC services in Nando? One-way analysis of variance (ANOVA) was used to answer this research question at 0.05 level of significance. The results obtained from the analysis are as presented in table 4 .

\begin{tabular}{|c|c|c|c|c|c|c|}
\hline Variable & Category & $\mathbf{N}$ & Mean & SD & & \\
\hline \multirow{9}{*}{$\begin{array}{c}\text { Occupational } \\
\text { status }\end{array}$} & House wife & 91 & 15.40 & 2.72 & & \\
\hline & $\begin{array}{c}\text { Civil } \\
\text { servant }\end{array}$ & 38 & 14.10 & 2.79 & & \\
\hline & $\begin{array}{l}\text { Business } \\
\text { women }\end{array}$ & 104 & 14.02 & 2.73 & & \\
\hline & $\begin{array}{l}\text { Privately } \\
\text { employed }\end{array}$ & 47 & 13.98 & 2.80 & & \\
\hline & Farmer & 82 & 13.49 & & & \\
\hline & $\begin{array}{l}\text { Source of } \\
\text { variance }\end{array}$ & $\begin{array}{c}\text { Sum of } \\
\text { Squares }\end{array}$ & Df & $\begin{array}{c}\text { Mean } \\
\text { Square }\end{array}$ & $\mathbf{F}$ & Sig. \\
\hline & $\begin{array}{l}\text { Between } \\
\text { Groups }\end{array}$ & 7.130 & 2 & 3.565 & 2.90 & .060 \\
\hline & $\begin{array}{l}\text { Within } \\
\text { Groups }\end{array}$ & 375.744 & 480 & 2.401 & & \\
\hline & Total & 382.874 & 482 & & & \\
\hline
\end{tabular}

Table 4: One-way analysis of variance of occupational status of women and the use of ANC services. Not significant at 0.05 level of significance, $\mathrm{df}=2,480$; critical F-value $=3.00$. 
One-way analysis of variance (ANOVA) was used to analyze the data. The result is presented in Table 4. As shown in Table 4, the calculated F-value of 2.90 is less than the critical F-value of 7.00 at 2 and 480 degrees of freedom, at 0.05 levels of significance by this results, the association between occupational status of women and the use of ANC services in Nando is not statistically significant. Therefore, we could conclude from the results that, women occupational status is not a significant factor to utilization of ANC facilities.

\section{Research question five}

How does economic status of women influence use of maternal health care services of primary health care centres in Nando? To answer this research question, One-way analysis of variance (ANOVA) was used at 0.05 level of significance. The results obtained from the analysis are as presented in table 5 .

\begin{tabular}{|c|c|c|c|c|c|c|}
\hline Variable & Category & $\mathbf{N}$ & Mean & SD & & \\
\hline & $\begin{array}{c}\text { Low } \\
\text { economic } \\
\text { status }\end{array}$ & 240 & 7.30 & 2.83 & & \\
\cline { 2 - 7 } & $\begin{array}{c}\text { Moderate } \\
\text { economic } \\
\text { status }\end{array}$ & 130 & 8.35 & 2.68 & & \\
\cline { 2 - 7 } Economic \\
status & $\begin{array}{c}\text { High } \\
\text { economic } \\
\text { status }\end{array}$ & 122 & 10.07 & 2.33 & Df & Square \\
\cline { 2 - 7 } & $\begin{array}{c}\text { Source of } \\
\text { variance }\end{array}$ & $\begin{array}{c}\text { Sum of } \\
\text { Squares }\end{array}$ & Df & F & Sig. \\
\cline { 2 - 8 } & $\begin{array}{c}\text { Between } \\
\text { Groups }\end{array}$ & 9.311 & 2 & 9.247 & 10.87 & $.001^{*}$ \\
\cline { 2 - 7 } & $\begin{array}{c}\text { Within } \\
\text { Groups }\end{array}$ & 4814.166 & 480 & 2.94 & & \\
\cline { 2 - 7 } & Total & 511.289 & 482 & & & \\
\hline
\end{tabular}

Table 5: One-way analysis of variance of economic status of women and the use of ANC services. * Significant at 0.05 level of significance, $\mathrm{df}=2$, 480; critical F-value $=3.00$.

One-way analysis of variance (ANOVA) was used to analyze the data. The result is presented in Table 5. As shown in Table 5, the calculated F-value of 10.87 is greater than the critical F-value of 7.00 at 2 and 480 degrees of freedom, at 0.05 levels of significance by this results, the association between economic status of women and the use of ANC facilities in Nando is statistically significant. Judging with the mean scores, it can be said that, women in low economic status have the least mean score value of $(\mathrm{M}=7.30$; SD $=2.83)$; than those in moderate economic status $(\mathrm{M}=8.35$; $\mathrm{SD}$ $=2.68$ ) which is less than the mean score of those in high economic status $(\mathrm{M}=10.07 ; \mathrm{SD}=2.33)$. The result implies that, women in high economic status are more likely to utilise ANC facilities than those in moderate economic status or low economic status.

\section{Discussion of Findings}

This study showed that the proportion of women that utilise ANC services in primary health care centres in Nando was high significantly high. This finding is in contrast with that reported by
Furuta and Salway in which the percentage of women that used antenatal care was low [12]. Similarly, Ejembi et al. also found that few mothers had modern antenatal care and delivery care during their last full term pregnancies and their major reason for not utilising maternal health care service was the cost [26].

Further findings from our study revealed that women who possess more decision making autonomy are more likely to utilise ANC services than those who do not posses decision making autonomy. This is consistent with the findings by Aigbe, where mothers who had more decision making autonomy and mothers who jointly decided with their husbands on choice of maternal health care services utilized orthodox health care services more than mothers whose husbands made the decision alone [14]. In the same vein, Ononokpono found that women who made joint decisions with their husbands on healthcare were two times more likely to attend ANC [23]. Chiang et al. found no significant linkage between women participation in household decision making and utilisation of maternal health care services [11]. There is a belief about the powerful influence of mothers and fathers in law but the writers observed a high level of autonomy in decision making by the rural women. One is tempted to associate this autonomy with the influence of social groups, a new wave of awareness and somehow with the increasing effect of feminism.

Our study showed that, women who possess more education are more likely to utilise ANC services than those who possess little or no education. This is in line with Furuta and Salway who found that the proportion of women with secondary and post-secondary education that used ANC and delivery care was significantly higher compared to women with no formal education [12]. Similarly, Ononokpono found that women with secondary or higher education level were 5.8 times more likely to utilise ANC services [23]. In the same vein, Aigbe found a significant association between education and the use of orthodox sources of ANC. This implies that the more educated the mothers, the more likely they will utilize orthodox sources of health care facilities. This outcome should be expected. Education ought to expose women to the importance of utilising health services in and out of pregnancies. Exposure to radio and television could be a contributing factor.

Further findings from the results conclude that, women occupational status is not a significant factor to utilization of ANC facilities. This finding disagrees with the study of Aigbe [14]. She reported that mothers who are engaged in formal economic sector (civil servants, bankers, lawyers etc.) utilized the orthodox sources of maternal health care services more when compared to the mothers engaged in non-formal economic sector (traders, hair dressers, tailors, farmers etc.) who utilized orthodox sources of maternal health care services. Similarly, Ononokpono found that women in formal employment and skilled manual workers were two times more likely to have four or more ANC visits than those with no employment [23]. The difference between their findings and our findings can be explained by the fact that this present study study was carried out in a rural area while the other studies were done in urban areas. 
This study also noted that women in high economic status were more more likely to utilise ANC facilities than those in moderate economic status or low economic status. This is in conformity with the works of Aigbe who found that the use of formal health institutions for antenatal care was higher in high social status [14]. The study is also in conformity with Koustuv et al. who in their study found that a high proportion of home delivery was reported by women below poverty level than their richer peers [27]. Ononokpono also found that women in rich or middle class household are more likely to utilise maternal health care services [23]. Attending clinic cost money. A woman in dependency may find it difficult to pay the expenses associated with attendance at the clinic. It is, therefore, logical that those with independent income would be higher in attendance than those without.

\section{Implication of the Findings to Nursing}

The findings from the study show that the higher the status of women the more likely they will utilise formal maternal healthcare services. The higher the level of education the more likely it is that the women will utilise health care services. The study also shows that decision making autonomy of women affects utilisation.

Since prompt and effective utilisation of maternal health care services reduces maternal morbidity and mortality, the implications of these findings are that nurses have to take on the role of health educators. They have to educate the women on the need to utilise formal health institutions for their reproductive health. Nurses can also engage in home visits in which the husbands and other relevant others will be seen and health educated on the importance of utilising maternal health care services for the reduction of maternal morbidity and mortality. Nurses also can campaign for women education and empowerment.

\section{Conclusion}

From the foregoing, this study has been able to examine association between women status and the utilization of maternal care services of primary health care centres in Nando. The utilization of maternal health care services in primary health care centres in Nando is above the average for ANC even though there are obvious gaps of delayed booking for ANC services and inadequate ANC attendance. Cost, poor awareness and perception remained the major reasons why some mothers are still patronizing unorthodox health facilities for ANC. Factors that influence the choice of ANC services were found to be women decision making autonomy, educational status and economic status. Women involvement in making decisions about their health increases their likelihood of utilizing maternal health services. Being able to make such decisions alone or jointly with husband creates a sense of responsibility within them as regards the use of ANC and delivery care. No doubt, mothers with higher educational status used maternal health services more because they have received information from a formal setup on the importance of accessing the services in an orthodox health facility such as a primary health centre in their community. Therefore, those who never had the privilege of attending a formal school or going past the primary level need an awareness campaign on the subject matter. Obviously, women with little or no education are a significant part of the proportion of women who do not enjoy the decision making autonomy concerning their health. Hence empowering women and promoting mothers' education would yield a better result in increasing the use of maternal health services. The Nando community comprises predominantly people in the lower socio-economic class. The theoretical and practical implication of this is that demand for antenatal care and delivery services generally declines with decreasing socio-economic status. It clearly means that maternal health services are services for which patients are willing to travel even long distances to receive, based principally on affordability and perceived quality service.

\section{Recommendations}

The study therefore recommends that:

- In order to increase the utilization of maternal health services for ANC, there is a strong need to focus on community and district-level interventions.

- Women should be empowered through education to enable them to take their place sufficiently in decision making in their families

- Husbands should be informed through sensitization programs organized by stakeholders on the need to give their wives a free hand in deciding places of ANC.

- It is particularly important for interventions to explore effective ways of increasing service utilization among low educated and poor women in rural areas who are the least likely to use maternal health services.

- $\quad$ Periodic monitoring of development with regards to maternal health should be conducted.

\section{Limitation}

- This investigation is community based and thus may limit its generalizability.

- Another limitation of the investigation might have been the use of a questionnaire to elicit information from respondents. This might have led to a bias in the responses.

- Due to inadequate frame, the sampling might have lacked a representative sample of the study population.

\section{References}

1. http://www.publichealth.hscni.net/sites/default/files/ Chapter\%206\%20Antenatal\%20care.pdf

2. Fawole OI, Adeoye IA (2015) Women's status within the household as a determinant of maternal health care use in Nigeria. Afr Health Sci 15: 217-225.

3. http://www.who.int/chp/topics/en/

4. WHO (2002) Antenatal care randomized trial: manual for the implementation of the new model, Geneva: WHO.

5. Andersen R, Newman JF (1973) Societal and individual determinants of medical care utilization in the United States. Milbank Mem Fund Q Health Soc 51: 95-124.

6. Rajesh kR, Prashant K, Chandan K, lucky Sing (2013) Factors associated with the utilisation of maternal health care services among adolescent women in Malawi. Home health care 
services quarterly 32 .

7. Anderson R (1995) Revisiting the behaviouralmodel and access to medical care: does it matter? Journal of Health and Social Behavior 36: 1-20.

8. Dairo MD, Owoyokun KE (2010) Factors affecting the utilization of antenatal care services in Ibadan Nigeria. African journal of reproductive health 12 .

9. Babalola S, Fatusi A (2009) Determinants of use of maternal health services in Nigeria--looking beyond individual and household factors. BMC Pregnancy Childbirth 9: 43.

10. Ahmed S, Creanga AA, Gillespie DG, Tsui AO (2010) Economic status, education and empowerment: implications for maternal health service utilization in developing countries. PLoS One 5: e11190.

11. Chiang C, Elshair IH, Kawaguchi L, Fouad NA, Abdou NM, et al. (2012) Improvements in the status of women and increased use of maternal health services in rural Egypt. Nagoya J Med Sci 74: 233-240.

12. Furuta M, Salway S (2006) Women's position within the household as a determinant of maternal health care use in Nepal. Int Fam Plan Perspect 32: 17-27.

13. Situ KC (2013) Women's autonomy and maternal health care utilization in Nepal. Master's thesis University of Tampere School of Health Sciences.

14. Aigbe GO (2011) Theoretical issues in the understanding of maternal health service utilisation in Lagos state, Nigeria. European Journal of Social Sciences 22.

15. UNFPA (2006) Maternal mortality update 2006: Expectation and delivery: Investing in midwives and others with midwifery skills. United Nations Population Fund.

16. Ajaegbu O (2013) Perceived challenges of using maternal health care services in Nigeria Arts and Social Science journal 1: ASSJ-65.

17. Federal Ministry of Health (2010) Integrating maternal, newborn and child health strategy. Abuja, Government of Nigeria.

18. Ogunjuyibe PO, Lissau A (2007) Perception and health seeking behaviour of Nigerian women about pregnancyrelated risks: strategies for improvement. Journal of Chinese clinical medicine 21.

19. WHO (2007) Factors influencing prenatal care use among low-income countries report. Geneva.

20. Federal ministry of health, Nigeria. (2002) Reproductive health resource and service survey. FMOH publications.

21. Kebebe E, Methanit G, Dawit S, Kassehum N (2012) Determinants of community based maternal health care service utilisation in south Omo pastoral areas of Ethiopia. Journal of medicine and medical sciences 3: 112-121.

22. Yar'zever IS, Said IY (2013) Knowledge and barriers in utilisation of maternal health care services in Kano State, Northern Nigeria. European Journal of Biology and Medical Science Research 1: 1-14.

23. Ononokpono D (2013) Multilevel Modelling of Determinants of Maternal Health Care Utlisation in Nigeria. Population Association of America 2013.

24. Polit D, Tetanobeck C (2008) Nursing research, generating and assessing evidence for Nursing Practice, (8th edn) Philadelphia.

25. Chinweuba A, Iheanacho P Agbapuonwu N (2013) Research \& Statistics in Nursing and Related Professions: Beginner's Guide. Enugu, El'Demak.

26. Ejembi CL, Alti-Muazu M, ChirdanO, Ezeh HO, Sheidu O, et al. (2009) Pattern of utilisation of health care services by Hausa women in rural Zaria. Journal of Community Medicine \& Primary Health Care 16: 47-54.

27. Dalal K, Shabnam J, Andrews-Chavez J, Mårtensson LB, Timpka T (2012) Economic empowerment of women and utilization of maternal delivery care in bangladesh. Int J Prev Med 3: 628-636.

28. Gwatkin D (2004) Socio-Economic Differences in Health, Nutrition, and Population - 45 Countries. The World Bank.

29. United Nations (UN) (2008) The Millennium development Goals Report 2008, New York.

30. WHO (2003) Antenatal care in developing countries: promises, achievement and missed opportunities: an analysis of trends, levels and differentials, 1990-2001.

31. WHO (2010) Mother-package: Implementing of the Safe Motherhood in developing countries, Geneva, 2010.

Citation: Okoronkwo I, Adeyemo F, Nnamdi N, Ada Nwaneri, Chjkaoodili I (2017). Women's Socio-Economic Status as a Determinant of Utilization of Antenatal Care in Primary Health Centres: A Case Study of Nando Community, Anambra East Local Government Area, Nigeria. Med Clin Res 2(1):1-7.

Copyright: (C2017 Ijeoma O, et al. This is an open-access article distributed under the terms of the Creative Commons Attribution License, which permits unrestricted use, distribution, and reproduction in any medium, provided the original author and source are credited. 